\title{
Uterine Tortion in Bovines: A Review Article
}

\author{
R. Prem Kumar ${ }^{1 *}$, R. Rajanna ${ }^{2}$ and R. Sunitha ${ }^{3}$ \\ ${ }^{1}$ Veterinary Dispensary, Madanahalli, Kolar, Karnataka, India \\ ${ }^{2}$ Veterinary Dispensary, Purlahalli, Challakere, Karnataka, India \\ ${ }^{3}$ Department of Veterinary Public Health and Epidemiology, \\ Veterinary College, Gadag, India \\ *Corresponding author
}

\begin{tabular}{|l|}
\hline Ke y w o r d s \\
$\begin{array}{l}\text { Bovines, Uterine } \\
\text { torsion, Dystocia, } \\
\text { Veterinarian, } \\
\text { Management }\end{array}$ \\
\hline Article Info \\
\hline $\begin{array}{l}\text { Accepted: } \\
\text { 20 May 2020 } \\
\text { Available Online: } \\
\text { 10 June } 2020\end{array}$ \\
\hline \hline
\end{tabular}

\section{A B S T R A C T}

Torsion of uterus is a common form of maternal dystocia in bovines. Both maternal and fetal causes are attributed to the etiology of uterine torsion. The entire length of pregnant uterine horn rotates on its longitudinal axis to the left (anticlockwise) or right side (clockwise) along with uterine body, cervix and cranial vagina mostly. In severe cases of uterine torsion, there is vascular compromise to foetus resulting in death of fetus in utero. Since uterine torsion frequently occurs during parturition, there is twisting of birth canal so delivery of fetus cannot occur without external aids. Uterine torsion is a diagnostic dilemma for Veterinarians and a difficult obstetric procedure for less experienced persons. Prognosis and future fertility of dam depends on severity and duration of uterine torsion and methods of handling. Diagnostic evaluation of the condition continues to be transrectal palpation of the broad ligaments which rotate along with the rotating uterus. The success of management of the condition lies in the correct and timely diagnosis and early referral to referral centers.

\section{Introduction}

Uterine torsion has been reported in most of the domesticated species. The condition was first described in 1766 by Boutrolle (Fleming, 1930). Uterine torsion is a well-known cause of dystocia in dairy cattle that often results in the necessity to consult the local veterinarian (Erteld et al., 2012). Torsion of the uterus occurs in a gravid uterine horn and is defined as the rotation or twisting of the gravid uterus on its longitudinal axis (Purohit et al., 2011). Uterine torsion occurs during last trimester of pregnancy (Murthy et al., 1999), second stage of labour at parturition (Prasad et al., 2000), rarely post-partum. Uterine torsion is one of the complicated causes of maternal form of dystocia in bovines especially in buffaloes culminating in dead of foetus and/or dam if not treated early. Uterine torsion must be 
considered as an emergency, early presentation of cases to referral units and early institution of therapy gives favourable prognosis to the dam and foetal survival. Diagnosis is based on per-vaginal and perrectal examination. Choice of treatment depends upon experience of veterinarian, severity of torsion and condition of dam and involves per-vaginal fetal rotation or rolling of dam or caesarean section. Current study reports etiology, diagnosis and treatment of Uterine Tortion.

\section{Predisposing factors}

Uterine torsion is more common in buffalo and cow than other domestic species. Incidence is noted to be highest in dairy cows and only rarely seen in beef cows (Frazer $e t$ al., 1996). Bos indicus cattle are stated to be the lowest risk group of cattle which may be due to the fact that insertion of broad ligament in these breeds change from ventral to dorsal position as it runs along the uterine body, allowing the uterus little freedom to move within the abdomen (Sloss and Dufty, 1980). Pluriparous animals are at a higher risk, possibly due to decrease in uterine and mesometrial tone is caused by multiple birth. A geographic association has also been recognized regarding the incidence of uterine torsion (Roberts, 1986).

\section{Etiology}

A number of theories have been promulgated for explaining the predisposition of bovine uterus to torsion, however maternal and fetal destabilizing factors behind occurrence of uterine torsion are not well understood (Ghuman, 2010). The main predisposing cause contributing to development of uterine torsion is thought to be unstable anatomical arrangement of bovine uterus which include 1) sub-ilial attachment of broad ligament 2) broad ligaments being attached along the lesser curvature of uterus, thus leaving greater curvature free 3) uterine horns not fixed by broad ligament and lying free 4) relatively small increase in length of broad ligament but the pregnant horn extends massively beyond area of attachment in advanced pregnancy (Ghuman, 2010). Higher incidence of uterine torsion in buffalo than cattle is partly due to big length of broad ligament in buffaloes which make pregnant uterus less stable. Weak musculature of broad ligament, lack of tonicity in broad ligament in pluriparous animals and enlargement of pregnant uterine horns are among other anatomical predisposition causes of uterine torsion. Unfilled rumen, capacious and pendulous abdomen seems to facilitate easy rotation of pregnant uterus in buffaloes compared to cattle and in pluriparous buffaloes compared to primiparous (Singh, 1991). Other factors include hilly terrain, slipping, sudden movement of dam, unsteady walk, while lying down bovines go down on forelegs first and while getting up, the hindquarters are elevated first, thus each times, the pregnant uterus is temporarily suspended in the abdominal cavity and is prone to torsion (Drost, 2007). Energetic movements of fetus during first stage labor, lack of fetal fluids and reduced rumen volume prior to parturition (Drost, 2007).

\section{Clinical signs}

The usual clinical signs are the onset of labor without delivery of fetus and/or fetal membranes and later regression of parturition signs (Singh et al., 1979). The animal may show signs of mild discomfort. The animal may adopt a rocking horse stance and show mild colic pain and constipation. Partial anorexia, dullness and depression may be evident (Ali et al., 2011). Restlessness and arching of back and colic may be seen in some buffaloes (Murty et al., 1999). In postcervical uterine torsion one or both lips of the 
vulva are pulled in because of rotation of the entire birth canal. Vaginal examination reveals twisting of the vaginal mucous membranes and the hand cannot be passed deeper into the anterior vagina which has a conical end in torsion with a degree of $180^{\circ}$ or more. In lesser degree torsions however, the fetus can sometimes be felt. The direction of the vaginal fold twisting is considered the evidence for the direction of torsion. On rectal examination, the twisted uterine horn can be felt and the broad ligament on the side of torsion is rotated downwards sometimes palpable under the uterus and the ligament on the opposite side is tense and stretched and crossing to the opposite side (Purohit et al., 2011a). The positive diagnosis of uterine torsion should thus, be based on the location of broad ligaments palpated per rectum. Animals at many locations may be presented to the obstetrician after varying times since the first onset of labour; hence, the clinical signs of shock and toxaemia may be evident depending upon the severity of torsion, previous handling, death of fetus and posttorsion complications.

\section{Clinical diagnosis}

Tentative diagnosis arrived at based on history and clinical signs. Moreover definitive diagnosis made by either per vaginal or per rectal examination or both.

\section{Based on history and clinical signs}

Tentative diagnosis is easy when the typical abnormal symptoms appears at the time of parturition or last trimester of gestation. Typical history of uterine torsion will indicate that animal with completed gestation, engorged teat with let down of milk and relaxation of pelvic ligaments, no rupture of the allantoic /amniotic water bags nor the appearance of fetus from the vulvar lips (Prabhakar et al., 1995).

\section{General and systemic signs}

Tachycardia, increased respiratory rate with oral breathing, restlessness, frequently lie down and gets up, severe abdominal pain (Colic) with kicking of the abdomen with her hind legs on the side of the pain (Noakes et al., 2001). Severe abdominal pain may suggestive of stretching of the broad ligaments from their normal anatomical position (Sloss and Dufty, 1980). Moreover increase in abdominal straining due to stimulation of stretch receptors present in the vaginal walls. If torsion cases untreated for several days, gradually the appetite decrease, rumen function ceases and faeces become hard (Srinivas et al., 2007).

\section{External sign}

Displacement of upper vulval commissure inward towards right or left side in accordance to side of uterine torsion. Vulval oedema with necrosis of vulvar mucosa due to compression/ strangulation of vaginal vein and lymphatic drainage, and a mild to moderate depression of lumbo-sacral vertebrae are not the valid features in all cases (Schonfelder et al., 2003).

\section{Per vaginal examination}

Most probably post and pre cervical torsion can be diagnosed by vaginal examination; however per rectal examination is indicated for confirmative diagnosis of pre cervical torsion.

\section{Post-cervical uterine torsion}

In normal pregnant animal, per vaginally no vaginal folds is palpable and flower like external os of the cervix easily accessible. In case of torsion vaginal folds are palpable due to rotation of cervical area of broad ligaments. Post cervical torsion can be easily diagnosed 
by per vaginal examination. In buffalo concern post cervical torsion was common. About 69-96 \% uterine torsion are post cervical in which the broad ligaments twist up to caudal to the cervix and involves rotation of anterior portion of vagina (Noakes et al., 2001). During vaginal examination, spiral folds or twists are present in vaginal wall along an reachable cervix indicative of post cervical with less than $180^{\circ}$ torsion (Noakes et al., 2001; Drost, 2007). Spiral folds or twists are present in the vaginal wall with not accessible cervix indicative of post cervical with more than $180^{\circ}$ torsion.

\section{Pre-cervical uterine torsion}

In pre cervical torsion, the twisting of broad ligaments lies on the body of uterus and does not include the cervix, so, during per vaginal examination vaginal folds are absent and cervix is easily reachable (Noakes et al., 2001)

\section{Pre and post cervical torsion}

Rarely clinically presented cases on per vaginal examination reveals vaginal fold with easy accessible cervix; however on per rectal examination reveals twisting of broad ligaments over the body of the uterus also.

\section{Per rectal examination}

In normal pregnant animal, the course of the broad ligaments palpated on the side of the uterus, where as in pre and post cervical torsion the orientation of broad ligaments is altered from their normal anatomical position and these can be felt by twisted uterus (Noakes et al., 2001). However direction of uterine torsion can be diagnosed by per rectal examination. Per rectal examination validate for both pre and post cervical torsion. The Clinical Diagnosis of Uterine Torsion in Bovines: An Update 964 direction of torsion may be of Right side (Clock wise) or Left side (Counter Clock wise) (Roberts, 2004) Right side broad ligament rotated along with uterus and pulled vertically downwards beneath the uterus, whereas left side broad ligament is tightly stretched above the uterus in right side torsion. Vice-versa for left side torsion. The examiners hand will move in a pouch like structure formed by crossing over of broad ligaments (Berchtold and Rusch, 1993; Noakes et al., 2001; Drost, 2007).

\section{Palpation of middle uterine artery}

Right and left middle uterine artery supplying blood to the uterus and its structure. It increases in diameter as pregnancy advances. Normally in pregnancy right middle uterine artery governs main function than left middle uterine artery due to right horn pregnancy in bovines.

It normally goes along with course of broad ligaments over the shaft of ilium. Cranial displacement of right and left middle uterine artery on the right and left side of the uterine torsion respectively, it may be due to stretching of broad ligaments (personal observation).

\section{Palpation of foetus}

At term normally foetal parts like head and foetal limbs can be easily palpable per rectally. Moreover per vaginally head and limbs with movement of foetus while pinching of foetal limbs over the cranial vaginal wall.

In torsion cases palpation of foetal parts is difficult due to stretching of broad ligaments and ventrally displaced uterus with foetus; Moreover after detorsion foetal parts like head and limbs are palpable through per rectal examination (personal observation) that indication of detorsion occur. 


\section{Fore arm entrance test}

At term per vaginal examination of normal pregnant animal allows three fourth of the fore arm to reach the cervix where as in torsion allows one fourth of the fore arm due to obstruction by vaginal folds. However it may vary from parity of animal and hand size of the obstetrician (Personal observation).

\section{Finger side test/ method}

Vaginal folds are not allowing the hands but allows the fingers. However through the vaginal folds, fingers go to the left side and dorsal face of the fore arm (hand) faced on right side of the animal indicative of Right side torsion. Vice-versa for Left side torsion. But, this method not valid for pre cervical torsion and adhesion formed cases. Moreover it can be confirmed by per rectal examination (Personal observation).

\section{Treatment}

Choice of treatment will depend upon experience of Veterinarian, severity of torsion and condition of dam.

\section{Per-vaginal foetal rotation}

It depends upon degree of torsion and amount of cervical dilatation (Sloss and Dufty, 1980). With rotation of 900 , the fetus can be easily rotated manually into a normal dorso-sacral position (Drost, 2007). If torsion is in the range of 90-1800 and cervix is dilated then this is the method of choice with rolling of dam being the next (Morten and Cox, 1968).

\section{Rolling of dam}

Rolling is indicated if dam is recumbent and the fetus is not approachable due to severity of torsion or if torsion has occurred before expected time of parturition (Roberts, 1986).
Before rolling, stabilization of dam is necessary with fluids and lifesaving corticosteroids. Rolling can be done with or without plank with varying degree of success. However, success rate is high when using plank (12 feet long and 10 inch wide) is placed on the upper paralumbar fossa. In Schaffer's method, principle is to rotate dam to same degree and direction to which the uterus has rotated, keeping the fetus fixed by fixing uterus with a plank (Schaffer, 1946). In brief, after ascertaining the side of torsion, animal is casted carefully in lateral recumbency on the side of direction of torsion and front and hind limbs are secured separately. The plank is placed on upper paralumbar fossa of dam in an inclined manner with lower end on ground. Next step is to slowly roll over the dam on its back. At the same time, an assistant stands on the plank to modulate pressure first on the left side (when animal is casted on right side), followed by ventral abdomen and lastly on right side. After each roll, effectiveness of roll is judged by vaginal or rectal examination (Ghuman, 2010). However thick skin of buffaloes causes skidding of the plank at the time of rolling. Moreover, pendulous abdomen of buffalo warrants greater pressure for fixation of pregnant uterus. For this, Sharma's modified Schaffer method is used which include change in dimension of plank (length 11.9 feet, width 9 inch and 2 inch thickness), while rolling plank is anchored by 1-2 assistant, an additional assistant modulate the pressure on the plank by pressing upper end of plank and buffalo is rolled quickly (Singh and Nanda, 1996). It is suggested that if torsion is not relieved after 3 rolls then failure should be admitted and surgery is indicated (Nanda et al., 1991).

\section{Caesarean section}

Most uterine torsions do not warrant surgical intervention and caesarean section is never 
performed as the first choice. Delayed uterine torsion (>72 hours) should be directly subjected to caesarean operation in order to avoid undue stress of rolling. Animal with a friable, septic uterus containing an emphysematous fetus is a poor candidate for abdominal surgery (Amer et al., 2008). While attempting caesarean, the cost of operation and value of the animal should be judiciously considered (Ghuman, 2010).

Conclusion of the study is as follows:

Although uterine torsion in cattle and buffalo is a condition of later gestation but occasionally can be encountered in early gestation too. Early diagnosis and management through caesarean section can be important tool to handle these cases. The adoption of aseptic surgery, use of antibiotics $\&$ anti-inflammatory drugs, fluid therapy after the surgery can be helpful in successful recovery and maintenance of reproductive health of the cattle.

\section{References}

Ali, A., Derar, R., Hussein, H.A., Ellah, M.R.A. and AbdelRazek, A.K.H. 2011.Clinical, hematological, and biochemical findings of uterine torsion in buffaloes (Bubalus bubalis). Animal Reproduction Science. 126(3-4): 168172.

Amer, H.A., Hashem, M.A. and Bader, A. 2008. Uterine twisting during pregnancy in buffaloes: relationship between clinical findings and biochemical indices. Journal of Applied Biological Science. 2: 31-39.

Berchtold, M. and Rusch, P. 1993. Birth interference from the mother. Animal obstetrics. pp. 222-44. (Eds) Richter J, Götze R, Grunert E and Arbeiter K. Parey Buchverlag Berlin.

Drost, M. 2007. Complications during gestation in the cow. Theriogenology. 68: 487-491.

Erteld, E.M., Wehrend, A. and GoerickePesch, S. 2012. Uterine torsion in cattle frequency, clinical symptoms and theories about the pathogenesis. Tierarztl. Prax. Ausg. G Grosstiere Nutztiere. 40(3): 167-175.

Fleming, G. 1930. Fleming's Veterinary Obstetrics. pp. 235-50. Baillière, Tindall and Cox, London

Frazer, G., Perkins, N. and Constable, P. 1996. Bovine uterine torsion: 164 hospital referral cases. Theriogenology.46: 739-58.

Ghuman, S.P.S. 2010. Uterine torsion in bovines: A review. Indian Journal of Animal Science. 80: 289-305.

Morten, D.H. and Cox, J.E. 1968. Bovine dystocia: A survey of 200 cases met within general practice. Veterinary Record. 83: 530-37.

Murty K K, Prasad V and Murty P R. 1999. Clinical observations on uterine torsion in buffaloes. Indian Veterinary Journal. 76: 643-45.

Nanda, A.S., Sharma, R.D. and Nowshehri, M.A. 1991. Outcome of various regimes of treatment of uterine torsion in buffaloes. Indian Journal of Animal Reproduction. 12: 197-200.

Noakes, D.E., Parkinson, D.J. and England, G.C.W. 2001.Maternal dystocias. Arthurs veterinary reproduction and obstetrics, (Ed.) Noakes D E. Saunders Harcourt, India.

Prabhakar, S., Dhaliwal, G.S., Sharma, R.D. and Nanda, A.S. 1995.Success of treatment in relation to milk letdown and pelvic relaxation in bovines with torsion of uterus. Indian Journal of Dairy Science. 48: 323-25.

Prasad, S., Rohit, K. and Maurya, S.N. 2000. Efficacy of laparohysterotomy and rolling of dam to treat uterine torsion in buffaloes. Indian Veterinary Journal. 
77: 784-86.

Purohit, G.N., Barolia, Y., Shekher, C. and Kumar, P. 2011. Diagnosis and correction of uterine torsion in cattle and buffaloes. Raksha Technology Review. 2: 11-17.

Roberts, S.J. 1986. Diagnosis and treatment of the various types of dystocia. Veterinary Obstetrics and Genital Diseases (Theriogenology).Woodstock, Edwards Brothers Inc. pp. 213-17.

Roberts, S.J. 2004. Diagnosis and treatment of the various types of dystocia. Veterinary Obstetrics and Genital Diseases (Theriogenology). pp. 213-17, Woodstock, Edwards Brothers Inc.

Schaffer, W. 1946. Schweizer Arch. Tierheilk 88: 44. Schonfelder, A. and Hasenclever, D. 2005. Cost-utility analysis of surgical obstetrics in bovines with torsio uteri intra partum. Berliner und Munchener Tierarztliche Wochenschrift. 118: 490-94.

Schönfelder, A., Richter, A. and Sobiraj, A. 2003.Prognostic indicators for conservatively incorrectable uterine torsion in the cow. Tierärztliche Umschau. 58: 512-17. Schönfelder A and Hasenclever D. 2005.
Singh, J., Nauriyal, D.C., Pattabiraman, S.R. and Sharma, R.D. 1979. Uterine torsion at mid-gestation in a buffalo. Indian Veterinary Journal 56: 700.

Singh, P. 1991. Studies on broad ligament in relation to uterine torsion in buffaloes. Thesis, Punjab Agriculture University, Ludhiana, India.

Singh, P. and Nanda, A.S. 1996. Treatment of uterine torsion in buffaloesModification of Schaffer's method. Indian Journal of Animal Reproduction. 17: 33-34.

Sloss, V. and Dufty, J.H. 1980. Obstetrical physiology. Obstetrical pathology. Obstetrical procedures. Handbook of Bovine Obstetrics. pp. 39, 105, 108-11, 180-83.

Sloss, V. and Dufty, J.H. 1980.Obstetrical physiology. Obstetrical pathology. Obstetrical procedures. Handbook of Bovine Obstetrics. pp. 39, 105, 108-11, 180-83. (Eds) Sloss V and Dufiy J H. Williams and Wilkins, Baltimore.

Srinivas, M, Sreenu, M., Lakshmi Rani, N., Subramanyam Naidu K. and Devi Prasad V. 2007. Studies on dystocia in graded murrah buffaloes: a retrospective study. Buffalo Bulletin 26: 40-45.

\section{How to cite this article:}

Prem Kumar, R., R. Rajanna and Sunitha, R. 2020. Uterine Tortion in Bovines: A Review Article. Int.J.Curr.Microbiol.App.Sci. 9(06): 2774-2780.

doi: https://doi.org/10.20546/ijcmas.2020.906.336 